\title{
RELAÇÕES DE CONSUMO NA PÓS-MODERNIDADE: O CONSUMO COLABORATIVO COMO INSTRUMENTO DE SUSTENTABILIDADE
}

\section{CONSUMER RELATIONS IN POST-MODERNITY: COLLABORATIVE CONSUMPTION AS A SUSTAINABILITY INSTRUMENT}

\author{
Mariana Ribeiro Santiago ${ }^{1}$ \\ Eduardo Buzetti Eustachio Bezerro²
}

\section{Resumo}

O presente artigo visa analisar o contexto das relações de consumo na pós-modernidade, bem como suas implicações na sustentabilidade. Nesse intento, partiu-se da anomalia verificada na origem do contrato e sua correlação nas relações de consumo na era pós-moderna, em que se vislumbrou o individualismo e egocentrismo das relações, na busca da satisfação instantânea, passando por uma abordagem sobre a função social e solidária, no viés da construção de uma sociedade justa, livre e igualitária. Na sequência, abordou-se a fundamentação do eco desenvolvimento, da sustentabilidade e da ferramenta do consumo colaborativo e suas implicações na sociedade, no meio ambiente e economia. Em conclusão, verificou-se que o contrato nas relações de consumo destina-se, a par do atingimento de interesses individuais, à manutenção dos pilares da sustentabilidade, o que se torna possível também pela via do consumo colaborativo. $\mathrm{O}$ método de investigação adotado no presente estudo foi a pesquisa bibliográfica, somado ao método dedutivo na abordagem.

Palavras-chave: Relações de consumo. Pós-Modernidade. Consumo colaborativo. Sustentabilidade.

\begin{abstract}
This article aims to analyze the context of consumer relations in postmodernity, and its implications for sustainability. In this attempt, it was based on the anomaly verified in the origin of the contract and its correlation in the relations of consumption in the postmodern era, in which the individualism and egocentrism of the relations were glimpsed, in the search for instant satisfaction, through an approach on the function social and solidarity, in the bias of the construction of a fair, free and egalitarian society. Following, the fundamentals of ecodevelopment, sustainability and the collaborative consumption tool and its implications in society, the environment and the economy were discussed. In conclusion, it was verified that the contract in the relations of consumption is aimed at the achievement of individualistic interests, but also for the maintenance of the pillars of sustainability, that is also possible through collaborative consumption. The research method adopted in the present study was the bibliographical, added to the deductive method in the approach.
\end{abstract}

Keywords: Consumer relations. Postmodernity. Collaborative consumption. Sustainability.

\footnotetext{
${ }^{1}$ Doutora em Direito pela Pontifícia Universidade Católica de São Paulo - PUCSP. Professora do Programa de Mestrado e Doutoradoem Direito da Universidade de Marília - UNIMAR. Editora-Chefe da Revista Argumentum e da Revista Thesis Juris. E-mail: mariana@nbsadvogados.com.br

2 Mestrando em Direito pela Universidade de Marília - UNIMAR. Professor da graduação em Direito da Universidade do Oeste Paulista - UNOESTE. E-mail: eduardobuzetti@hotmail.com
} 


\section{INTRODUÇÃO}

As relações de consumo são inatas ao ser humano, daí porque Gilles Lipovetsky afirma que constituímos o homo consumericus (LIPOVETSKY, 2007, p. 357). Tal quadro, contudo, potencializa-se na chamada pós-modernidade, trazendo consigo a preocupação social sobre a celebração dos contratos, uma vez que o avanço tecnológico, o progresso econômico, social e político dos países, bem como a reestruturação da atividade empresarial repercutiram na seara da liberdade contratual.

Sem o intento de esgotar a temática, mas propor reflexões críticas e rememorar discussões de outrora, esta pesquisa visa analisar a liberdade contratual nas relações de consumo, numa visão clara da pós-modernidade, o que resulta no estudo do direcionamento do modo ou hábitos de consumo na pós-modernidade e a necessidade de um novo modelo de consumo ou ressuscitação de um modelo arraigado na vida social, mas sob uma nova ótica, visando a preocupação com a sustentabilidade.

O panorama da função social e da função solidária da empresa proporcionam a análise da sustentabilidade, com fundamento da solidariedade, seja nos aspectos social, ambiental ou econômico, e é nessa perspectiva que se justifica o trabalho noticiado, haja vista as implicações nas gerações presentes e futuras.

Nesse sentido, no primeiro capítulo trataremos da nova dinâmica que resulta para as relações de consumo num quadro de pós-modernidade; no capítulo segundo, abordaremos o tratamento da função social e solidária da empresa como fundamentos das relações contratuais pós-modernas; no derradeiro capítulo, desenvolveremos o raciocínio da utilização da sustentabilidade como vetor estruturante das relações de consumo pós-modernas, à luz da experiência do consumo colaborativo.

Em relação às questões metodológicas, destacamos que, como método de pesquisa, serão utilizados os critérios histórico e funcionalista, para investigar a influência dos fatos passados no atual quadro social e a função que os indivíduos consumistas exercem no todo, tendo como método de investigação a pesquisa bibliográfica e método de abordagem dedutivo. 


\section{A NOVA DINÂMICA DAS RELAÇÕES DE CONSUMO NO CONTEXTO DA PÓS- MODERNIDADE}

A convivência em sociedade, cuja manutenção da ordem é inexorável, vez que o conflito de interesses é inato às relações humanas, pressupõe a existência de normas e regras de convivência que disciplinem direitos e obrigações.

Para a harmonia dos interesses individuais, criaram-se mecanismos de contração de obrigações, cujas várias formas podem suceder: repressão à prática de atos ilícitos, por ação ou omissão, dolosa ou culposa, e celebração de negócios jurídicos.

Consoante ensina Giuseppe Stolfi, entende-se pelo negócio jurídico: "la manifestazione di voluntà di una più parti che mira a produrre un efetto giuridico e cioè la nascita o la modificazione o l'accertamento oppure l'estenzione di un diritto subbietivo"3 (STOLFI, 1957, p. 460). Já a expressão contrato possui acepção singular, ora tratada simplesmente como contrato, ora dita como convenção, e ainda, ora definida como pacto.

Historicamente, com espeque no direito romano, a convenção refletia como sendo todo e qualquer negócio jurídico celebrado entre as partes, em que existam ou não direitos e obrigações, e que permitia sua exigibilidade coercitiva judicialmente, ao passo que no contrato havia a característica de contração de direitos e obrigações pelas partes, embora também permitisse a exigibilidade via judicial. Já o pacto era considerado como a avença de vontades cujo interesse não estava previsto em lei; logo, inexistia possibilidade de exigibilidade por meio de ação judicial.

O Código Civil brasileiro de 2002, ao apresentar os requisitos intrínsecos do negócio jurídico, dispõe no artigo 104, que sua celebração pressupõe a existência de partes capazes, objeto lícito, possível, determinado ou determinável, a par de forma prevista ou não proibida legalmente.

Sem maiores digressões sobre cada um dos elementos, é claro que, ainda que não expresso em lei, é necessário como elemento indissociável do negócio jurídico a existência da vontade de contratar, vontade que deve ser obtida de maneira livre, sob pena de nulidade ou anulabilidade, conforme a gravidade do defeito ou vício manifestado, e respeitada também a autonomia dessa vontade.

\footnotetext{
3 "A expressão da vontade que tem como objetivo produzir um efeito legal, ou seja, o nascimento, a modificação, a notificação ou a extensão de um direito subjetivo" (tradução livre).
} 
No campo da autonomia da vontade, merece destaque que a ótica sob a égide do Estado Liberal, em que a concorrência era absolutamente reinante e sem limites, e que celebração contratual também não possuía entraves, era comum a máxima do laissez-faire, laissez aller, laissez passer, expressões francesas que consistiam em deixai fazer, deixai ir, deixai passar, tese do Estado Mínimo de inspiração norte-americana, no século XIX e início do século XX (MORAIS, 2016).

Para Enzo Roppo (1998, pp. 300-301), a validade do contrato está atrelada à necessidade da tutela da confiança, que sugere estabilidade aos negócios, certo que a objetivação do contrato e do próprio direito contratual está baseada mais na declaração da vontade do que propriamente na vontade.

Mas a liberdade contratual nunca foi absolutamente ilimitada, restando ainda mais contida sob a égide do atual Código Civil, pois deve estar pautada na boa-fé dos contratantes e da função social dos contratos (artigos 421 e 422).

Pondera Arnaldo Rizzardo (2015, p. 61) que na celebração do contrato tem predomínio a finalidade social, vedadas cláusulas abusivas ou que atentem contra valores superiores, como moradia, habitação, vida, saúde, formação, respeito e dignidade, como, por exemplo, cláusulas que tomem a integralidade do salário ou da moradia; que submeta o indivíduo à prestação de serviços em jornada superior a oito horas diárias, salvo excepcionalidades.

Rizzardo (2015, p. 73) esclarece, também, que a normatização limita a liberdade contratual, vez que se assim se admitisse, o indivíduo agiria sob o interesse próprio, e não no interesse social, numa hipótese sintomática à luz da psicanálise, em que o indivíduo agiria, invariavelmente, em detrimento da ordem jurídica.

No âmbito das relações consumeristas, a sociedade vem cada dia mais utilizando o contrato como meio de satisfação do interesse pessoal, e justamente aqui cabe perquirir em que parâmetros estão pautadas as relações de consumo na sociedade pós-moderna e globalizada.

Anthony Giddens (1991, p. 16) menciona que o capitalismo tornou a sociedade moderna numa sociedade móvel, inquieta, sedimentada no resultado do parâmetro "investimento-lucro-investimento", cuja tendência implica no lucro, que propicia a expansão do sistema capitalista.

Entende Giddens que a transformação social moderna não decorre só do capitalismo, nem só do industrialismo, mas da multidimensionalidade, tudo para atender às necessidades humanas (GIDDENS, 1991, p. 17). 
Entretanto, a despeito do capitalismo ou industrialismo, na visão de Zygmunt Bauman, as relações de consumo pautam-se sobre a concepção do que é útil ou inútil, de acordo com o que é apresentado ao consumidor, predefinido como sendo de aceitação moderna. Segundo o autor a expectativa de vida de um produto é definida na estratégia de marketing e no cálculo de lucros; com efeito, tende a ser preconcebida e prescrita na prática dos consumidores, mediante a apoteose das novas ofertas, atuais, e a difamação das ofertas antigas, desatualizadas (BAUMAN, 2008, pp. 30-31).

Na interpretação de Bauman (2008, pp. 30-31), a relação consumerista na modernidade representa uma inegável instabilidade, ante a busca da satisfação do interesse privado, onde tudo o que não mais é aceito como útil deve ser desprezado.

Nesse sentido, obtempera o autor que na pós-modernidade o consumidor resolve a sua insatisfação com o descarte dos objetos que não mais Ihe trazem satisfação. Nessa perspectiva, despreza-se a durabilidade dos produtos, igualando as definições de "velho" a "defasado". De todo modo, impróprios à utilização, devem ser descartados como "lixo" (BAUMAN, 2008, p. 31).

Vivemos em uma realidade em que a sociedade pratica o hábito do "descarte" do que Ihe é sugerido como velho, inadequado ou defasado, e na busca incessante do ter e do poder, pois apenas assim, pela ótica da sociedade de consumo é que se está vivendo em plenitude.

Ocorre que essa ideologia do consumo, quiçá um "fetiche", oferece uma verdadeira rotinização do comportamento individual, tal como chamada por Bauman (2008, p. 42), o que fere a valorização da liberdade contratual, pois embora diante de uma liberdade contratual formalmente livre, a manifestação de vontade do consumidor the é imposta por uma praxis ou regra de convívio social, em que o consumo ostensivo é erigido a um patamar superior, para definição sobre o modo e com quem tais pessoas vão se relacionar.

Rachel Botsman pondera que os reflexos do consumo elevado trouxe a formação de distúrbios psicológicos que podem ser definidos como "cárcere do consumo" (BOTSMAN; ROGERS, 2011, pp. 05-06).

Neste contexto, tornou-se sedutora a ideia de que a celebração do contrato e interpretação de seu objeto é algo distante do interesse moral, meramente financeiro, cuja causa pode estar ligada à concepção do interesse do consumo pelo consumo, e não de sua utilidade à vida humana, para seu desenvolvimento, progresso e desempenho das atividades no convívio social.

Quiçá por isso tenha Bauman concebido que o consumismo se contrapõe às formas de convívio de outrora, e que associa a felicidade não mais à satisfação de necessidades vitais ou 
úteis, mas a uma intensidade de desejos sempre crescente, desejos os que resultam no uso imediato e rápida substituição dos objetos, tudo visando à satisfação pessoal (BAUMAN, 2008, p. 44).

Observa-se, assim, que o direcionamento das novas relações de consumo foi alterado, e o que antes era buscado pela sociedade para a satisfação de uma vontade ou interesse necessário, hoje é buscado com fundamento em uma satisfação instantânea, fugaz e substituível, denotando a necessidade da utilização de novos mecanismos para a contribuição à construção do consumo sustentável.

\section{A FUNÇÃO SOCIAL E A FUNÇÃO SOLIDÁRIA COMO FUNDAMENTOS DAS RELAÇÕES CONTRATUAIS PÓS-MODERNAS}

A propriedade é direito fundamental, mas assim como todo direito, não é absoluto. À época do direito romano, a propriedade possuía traços individualistas, o que também se verificou na Revolução Francesa, em 1789.

O Estado Liberal foi marcado pela ampla liberdade, o que facilitou o desempenho da atividade empresária e atos de comércio, fazendo com que o empresário alcançasse o pilar do capitalismo industrial, a obtenção de lucros cada vez maiores. Não se importava com o indivíduo como consumidor, sobre seu desenvolvimento, sobre as consequências da atividade empresária na sociedade e eventuais distúrbios gerados pela produção incansável de bens e riqueza. Nessa época, o Estado conferia liberdades negativas, porquanto tudo permitia e em nada, ou quase nada, intervia. Os efeitos disso foram inegáveis: permitia-se fazer tudo o que não fosse considerado crime; a igualdade entre os indivíduos era inalcançável, sobretudo, porque havia a secção entre classes (burgueses e plebeus), e por isso, concebeu-se igualdade meramente formal; a economia somente favorecia àqueles que possuíam poder de consumo.

O Estado Liberal, a partir da Constituição Francesa de 1979, preocupado com a proteção dos direitos humanos, e na ideologia da igualdade, passou a permitir a observância estatal (liberdade negativa) na maioria dos fatos sociais; entretanto, começou a construir a intervenção na ordem econômica, visando obter o equilíbrio entre a livre-iniciativa e a dignidade humana. Conforme Norberto Bobbio, a ingerência do Estado Liberal é a mais restrita possível (BOBBIO, 200, p. 101).

O individualismo, a concentração de poder, e a ausência de intervenções do Estado para garantir a igualdade material e a dignidade da pessoa humana favoreceram a crítica ao 
sistema de governo, a queda e o nascimento do Estado Social, este, preocupado com a realização de políticas públicas para garantir o desenvolvimento social, erradicar a marginalização e a pobreza, e propiciar a construção de uma sociedade mais justa e efetivamente igualitária, criando, para tanto, mecanismos de incentivo, chamadas de liberdades positivas ou prestações positivas, vislumbradas pelo intervencionismo estatal.

Nesse quadro, a propriedade que era vista como direito individual, passou a ser considerada como algo com fim social, e por isso, construiu-se o que se denominou de função social da propriedade, cuja origem é controvertida.

Consoante o entendimento de León Diguit:

a propriedade deixou de ser o direito subjetivo do indivíduo e tende a se tornar a função social do detentor da riqueza mobiliária e imobiliária; a propriedade implica para todo detentor de uma riqueza a obrigação de empregá-la para o crescimento da riqueza social e para a interdependência social. Só o proprietário pode executar uma certa tarefa social. Só ele pode aumentar a riqueza geral utilizando a sua própria; a propriedade não é, de modo algum, um direito intangível e sagrado, mas um direito em contínua mudança que se deve modelar sobre as necessidades sociais às quais deve responder. (DIGUIT, 2016, pp. 239-240)

A primeira Constituição Brasileira a abordar a função social da propriedade foi a de 1934 (artigo 113), o que se manteve nas constituições posteriores. Na Constituição Federal de 1988, a função social da propriedade está prevista no artigo 5o, inciso XXIII, e também há regramento no artigo 170, inciso III, da Carta Magna, quando disciplina os valores da ordem econômica, colocando, portanto, limites ao exercício da atividade empresarial.

A propriedade, portanto, não pode ser utilizada pelo seu titular ou possuidor para obtenção de proveito próprio, mas que ao exercer seus direitos deve lembrar que está integrado à sociedade, a qual não deve ser prejudicada de nenhuma forma por atos do proprietário.

A previsão expressa, no atual Código Civil, do princípio da função social da propriedade (Art. 1.228, §1으) e também do contrato (Art. 421) vem arrematar o entendimento da socialidade, aplicando, específica e expressamente, os preceitos da justiça social, consolidando entre nós, definitivamente, a visão da autonomia privada limitada (SANTIAGO; CAMPELLO, 2016, p. 128).

Embora sem menção no texto constitucional, a função social ganha seus contornos também no direito empresarial, como sendo função social da empresa, no sentido de que o 
empresário não pode exercer sua atividade apenas para a produção de riqueza e obtenção de lucro, mas também deve gerar desenvolvimento social.

Vale ressaltar, ainda, que a função social da empresa já podia ser deduzida dos arts. 116, parágrafo único ${ }^{4}$, e $154^{5}$, da Lei das Sociedades por Ações (6.404/76), embora se trate de legislação específica apenas sobre uma espécie societária (SANTIAGO; CAMPELLO, 2016, 130).

Vários diplomas legais estão a demonstrar a intervenção do estado para assegurar que as relações jurídicas não produzam efeitos individualistas, mas que devem atenção aos reflexos produzidos na coletividade.

Conforme explica Mariana Ribeiro Santiago e Lívia Gaigher Bósio Campello:

[...] podemos citar a lei da usura (impedindo a cobrança de juros extorsivos), a lei do inquilinato (protegendo o inquilino, considerado parte mais fraca no contrato de locação), a lei de luvas (visando proteger o locatário especificamente nas locações comerciais), o Código de Defesa do Consumidor (dispensando proteção especial ao consumidor) etc. (SANTIAGO; CAMPELLO, 2016, pp. 127-128)

E sobre a noção da função social no contexto brasileiro, Calixto Salomão Filho explica que:

No Brasil, a idéia (sic) da função social da empresa também deriva da previsão constitucional sobre a função social da propriedade (art. 170, III). Estendida à empresa, a idéia (sic) de função social da empresa é uma das noções de talvez mais relevante influência prática na transformação do direito empresarial brasileiro. É o princípio norteador da 'regulamentação externa' dos interesses envolvidos pela grande empresa. Sua influência pode ser sentida em campos tão díspares como direito antitruste, direito do consumidor e direito ambiental.

Em todos eles, é da convicção da influência da grande empresa sobre o meio em que atua que deriva o reconhecimento da necessidade de impor obrigações positivas à empresa. Exatamente na imposição de deveres positivos está o seu traço característico, a distingui-la da aplicação do princípio geral neminem laedere. Aí está a concepção social intervencionista, de influência reequilibradora de relações sociais desiguais". (2003, pp. 08-09) (grifo do autor)

A função social da empresa, portanto, exige do empresário que sua atividade produza lucro e, ao mesmo tempo, reverta-se em benefícios que favoreçam o desenvolvimento social e econômico.

\footnotetext{
4 "O acionista controlador deve usar o poder com o fim de fazer a companhia realizar o seu objetivo e cumprir sua função social, e tem deveres e responsabilidades para com os demais acionistas da empresa, os que nela trabalham e para com a comunidade em que atua, cujos direitos e interesses deve lealmente respeitar e atender".

5 "O administrador deve exercer as atribuições que a lei e o estatuto Ihe conferem para lograr os fins e no interesse da companhia, satisfeitas as exigências do bem público e da função social da empresa".
} 
Ocorre que, no atual contexto, não basta falar sobre o cumprimento da função social da empresa, porque insuficiente ao alcance da tutela jurídica na pós-modernidade. A preocupação hoje perpassa pelo que passou a conceber como função solidária da empresa.

A função solidária da empresa decorre do princípio da solidariedade estampado no artigo 3, inciso I, da Constituição Federal, e é marcado pela necessidade da construção de uma sociedade livre, justa e igualitária.

De acordo com o ensinamento de José Afonso da Silva:

O que a Constituição quer, com esse objetivo fundamental, é que a República Federativa do Brasil construa uma ordem de homens livres, em que a justiça distributiva e retributiva seja um fator de dignificação da pessoa e em que o sentimento de responsabilidade e apoio recíprocos solidifique a ideia de comunidade fundada no bem comum. Surge aí o signo do Estado democrático de direito, voltado à realização da justiça social, tanto quanto a fórmula liberdade igualdade e fraternidade o fora no Estado liberal proveniente da Revolução Francesa. (SILVA, 2009, pp. 46-47)

Sob a ótica de José Afonso da Silva, da qual permissa venia comungamos, a justiça retributiva e os valores da liberdade, igualdade, fraternidade e dignidade da pessoa humana são valores a serem construídos, ou seja, não estão prontos. Ao marco da Constituição Federal de 1988, não tínhamos e ainda hoje continuamos a não ter efetivamente uma sociedade plenamente justa, livre e igualitária.

A solidariedade ingressa no sistema jurídico como uma forma de atribuir significado ao próximo, despertando no indivíduo o reconhecimento da existência do outro, porque estimula em cada um a consciência perceptiva do ambiente social. Torna-se, assim, um novo paradigma para o direito, que, visando melhorar o Estado, a sociedade e a qualidade de vida dos cidadãos, implica um sistema jurídico que valoriza a dignidade plena do ser humano e a responsabilidade social de todos, no qual não se encaixam a indiferença social e o egoísmo individual exacerbado (CARDOSO, 2010, pp. 109, 116 e 122).

Por outra perspectiva, a solidariedade, ao buscar a igualdade entre os indivíduos como fim, pressupõe situações de desigualdade, pois age exatamente no espaço da diferença entre os mesmos. Esta desigualdade é o objeto da solidariedade (DI LORENZO, 2010, p. 132).

Referência no tema da solidariedade, Edgar Morin (2005, p. 36) ensina que

em nosso mundo de homens, no qual as forças de separação, recolhimento, ruptura, deslocamento, ódio, são cada vez mais poderosas, mais do que sonhar com a harmonia geral ou com o paraíso, devemos reconhecer a necessidade vital, social e ética de amizade, de afeição e de amor pelos seres humanos, os quais, sem isso, viveriam de hostilidade e de agressividade, tornando-se amargos ou perecendo. 
Ao relacionar solidariedade e justiça, Habermas (2002, pp. 75-76) afirma que:

A justiça concebida deontologicamente exige, como sua outra face, a solidariedade. Não se trata, neste caso, de dois momentos que se complementam, mas de aspectos da mesma coisa. Toda moral autônoma tem que resolver, ao mesmo tempo, duas tarefas: ao reivindicar trato igual, e com ele um respeito equivalente pela dignidade de cada um, faz valer a inviolabilidade dos indivíduos na sociedade; e ao mesmo tempo em que exige a solidariedade por parte dos indivíduos, como membros de uma comunidade na qual são socializados, protege as relações intersubjetivas de reconhecimento recíproco. A justiça refere-se à igualdade da liberdade dos indivíduos que se determinam a si mesmos e que são insubstituíveis, enquanto a solidariedade refere-se ao bem, ou à felicidade dos companheiros irmanados em uma forma de vida intersubjetivamente compartilhada, e deste modo também à preservação da integridade dessa forma de vida. As normas não podem proteger um sem o outro, isto é, não podem proteger a igualdade de direitos e as liberdades dos indivíduos sem o bem do próximo e da comunidade a que eles pertencem.

Ao passo que pela função social da empresa o empresário deve atender às disposições legais e estatutárias, vez que caso venha a causar danos à coletividade ou distúrbios sociais poderá sofrer a intervenção estatal, na função solidária da empresa exige-se mais, que a atividade da empresa proporcione o desenvolvimento social, econômico, e também, respeite a preservação do planeta, tudo para garantir a existência de recursos para as gerações presentes e assegurar condições mínimas da existência de gerações futuras.

Ponderam Vladmir Oliveira da Silveira e Elenice Baleeiro Nascimento Ribeiro que a diferença entre a função social e a solidária da empresa está no sentido de que a primeira serve de limitação à da propriedade privada, atenuando o efeito meramente patrimonial e individualista, que caracterizam sua tutela, enquanto que na segunda, direciona-se à tutela de direitos difusos e coletivos, tais como direitos consumeristas e ambientais (SILVEIRA; RIBEIRO, 2016, p. 10).

No estágio atual das relações do contexto da pós-modernidade, calcadas no consumo elevado, com a extração de recursos naturais não renováveis em larga escala, produção de resíduos e lixo como nunca se foi visto, evidencia-se a grande possibilidade de transformação da existência humana em um verdadeiro caos. Em face disso, torna-se cada vez mais necessária a construção de novas formas de consumo, lastreadas na solidariedade social, numa visão instrumental de sustentabilidade.

\section{A SUSTENTABILIDADE COMO NORTEADORA DAS RELAÇÕES DE CONSUMO PÓS- MODERNAS E A EXPERIÊNCIA DO CONSUMO COLABORATIVO}


A preocupação com a preservação do planeta e, consequentemente, da existência humana, além da utilização dos recursos naturais de modo racional, implica no estudo da sustentabilidade como vetor das relações sociais.

Sob esse prisma, a própria Constituição Federal de 1988, atenta à necessidade de garantia de condições de habitabilidade das gerações presentes e futuras, erigiu como princípio o "desenvolvimento sustentável", vez que ao tempo em que assegura o direito comum ao meio ambiente ecologicamente equilibrado, impõe ações públicas e sociais para a defesa e preservação do Estado Brasileiro, como componente do planeta.

Por outro lado, o princípio da solidariedade social, previsto no artigo 3, inciso l, da Constituição Federal, ao orientar que a atividade empresária deva proporcionar o crescimento e o desenvolvimento social das gerações presentes e futuras, traz a necessidade do atendimento à sustentabilidade.

A sustentabilidade tem sede na expressão ecodesenvolvimento, utilizada pela primeira vez em evento realizado pela Organização das Nações Unidas em Estocolmo, Suécia, em 1972, pelo secretário da conferência, Maurice Strong, mas foi popularmente difundida nos estudos de Ignacy Sachs, a partir de 1974, para quem o ecodesenvolvimento seria a gerência da natureza "de forma a assegurar aos homens de nossa geração e à todas as gerações futuras a possibilidade de se desenvolver" (SACHS apud FILHO, 2011).

Após novos debates, já na década de 1980, solidificou-se a expressão sustentabilidade voltada à proteção ambiental, fulcrada na difícil tarefa de harmonizar a exploração dos recursos naturais e a manutenção do equilíbrio ambiental, de modo que se atenda às expectativas atuais, sem comprometer a qualidade da vida imediata, além da preservação do planeta para as gerações futuras (SANTIAGO; MACHADO, 2015).

Nesse prisma, ao tratar do tema da sustentabilidade, Juarez Freitas (2012, p. 41) ensina que:

trata-se do princípio constitucional que determina, com eficácia direta e imediata, a responsabilidade do Estado e da sociedade pela concretização solidária do desenvolvimento matéria e imaterial, socialmente inclusivo, durável e equânime, ambientalmente limpo, inovador, ético e eficiente, no intuito de assegurar, preferencialmente de modo preventivo e precavido, no presente e no futuro, o direito ao bem-estar.

E continua o referido autor (FREITAS, 2012, pp. 29 e 31):

a sustentabilidade não pode ser considerada um tema efêmero ou de ocasião, mas prova viva da emergência de uma racionalidade dialógica, interdisciplinar, criativa, antecipatória, medidora de consequências e 
aberta. (...) As grandes questões ambientais do nosso tempo (a saber, o aquecimento global, a poluição letal do ar e das águas, a insegurança alimentar, o exaurimento nítido dos recursos naturais, o desmatamento criminoso e a degradação disseminada do solo, só para citar algumas) devem ser entendidas como questões naturais, sociais e econômicas, simultaneamente, motivo pelo qual só podem ser equacionadas mediante uma abordagem integrada, objetiva, fortemente empírica e, numa palavra, sistemática.

A concepção da sustentabilidade viu-se transformada a partir dos estudos de John Elkington, que desenvolveu o que se denominou de tripé da sustentabilidade, a teoria do triple bottom line, com a sigla people, planet and profit, para identificar que a preocupação da sustentabilidade deve harmonizar a coexistência do povo, do planeta, e do lucro, resultado do mundo capitalista (ELKINGTON, 2011, pp. 02-488).

Nesse viés, identificou Elkington que a sustentabilidade comporta três sentidos, devendo abranger a sustentabilidade social, a sustentabilidade ambiental e a sustentabilidade econômica, ou seja, a atividade empresária deve constituir em um negócio justo e igualitário, com a possibilidade de diminuição da miserabilidade e da exploração humana; destarte, deve a atividade empresária buscar prevenir danos ao meio ambiente utilizar dos recursos naturais somente no que for indispensável ao exercício do negócio, para que se mantenha condições dignas da existência das presentes gerações, bem como, proporcione a habitabilidade do planeta para as gerações futuras; e por fim, deve também a atividade empresária preocupar-se com as condições de desenvolvimento econômico, evitando práticas que impliquem em superendividamento e aumento de índices de inadimplência (ELKINGTON, 2011, pp. 02-488).

A observância ao tripé da sustentabilidade no contexto da pós-modernidade inclui a análise de meios alternativos para a compatibilização ou harmonização do consumo e da preservação do desenvolvimento social e econômico, sem olvidar da preocupação com a preservação dos recursos naturais e da exploração indispensável à existência humana, onde se faz necessária a exposição acerca da experiência do consumo colaborativo.

Malgrado não possa ser definido como novidade, tampouco na realidade brasileira, o consumo colaborativo é uma das principais ferramentas de conscientização sobre a desnecessidade da exploração desenfreada de recursos naturais para a manutenção da "necessidade" do consumo como meio de o indivíduo sentir-se integrado e participativo da vida social, reflexos da era pós-moderna, em que não somos valorizados como coletividade, mas marcados pelo individualismo, e ânsia do "ter" em detrimento dos valores essenciais do "ser".

Trata-se, outrossim, de uma forma alternativa de economia, chamada de economia compartilhada, fulcrada numa ideologia solidária, cooperativa ou associativa, ou seja, necessita 
da confiança no próprio indivíduo, já que escapa à tutela do Código de Defesa do Consumidor, quanto aos direitos coletivos lato sensu.

Vislumbram-se práticas como bancos populares, sistemas de trocas ou clubes de trocas, cooperativas e associações, que sem fins lucrativos, auxiliam outras associações ou associados que necessitem de sua atuação para a fruição de produto ou serviço.

De fato, mostra-se necessária uma mudança na mentalidade sobre o uso de produtos e já se difundem mundialmente sistemas lastreados na ideia de que se pode obter benefícios dos bens sem possuí-los definitivamente, o que repercute no modelo de propriedade privada individual. O que se percebe é que, se um produto de uma empresa é compartilhado entre pares, isso maximiza a sua utilidade, sem que os usuários devam arcar com o ônus da propriedade, como pagar completamente pelo valor do produto, manutenção ou seguro (BOTMAN; ROGERS, 2011, p. 61).

As motivações daqueles que participam desse tipo de economia são diversas. Alguns, mais altruístas, na defesa do "consumo verde", mostram-se preocupados com as gerações futuras, os aspectos sociais ou simplesmente buscam um relacionamento mais estreitos com pessoas e não marcas. Outros estão focados numa urgência prática de economizar dinheiro ou tempo, ou seja, mantendo a crença no interesse próprio (BOTSMAN; ROGERS, 2011, p. 60).

As iniciativas de economia solidária e consumo colaborativo em diferentes partes do mundo, em verdade, apresentam semelhanças com algumas tendências históricas e culturais de organização de grupos sociais do passado, que ressurgem ou se revigoram na modernidade, combinando a dimensão comunitária tradicional e a moderna dimensão pública na sua ação (FRANÇA FILHO; LAVILLE, 2004, pp. 17-18).

Obviamente, não se prega, através deste estudo, a extinção, por exemplo, da compra e venda, o que seria incompatível com o sistema capitalista, mas apenas o resgate e a valorização de vias alternativas de aquisição e utilização de bens, mais compatível com os paradigmas da sustentabilidade econômica, social e ambiental (CAMPELLO; SANTIAGO, 2013).

O fio condutor do consumo colaborativo ou solidário é a relação de confiança, e seu desenvolvimento trouxe a sua divisão em três critérios ou sistemas: sistema de serviços de produtos; mercado de redistribuição e o próprio estilo de vida colaborativo. Tais critérios foram desenvolvidos por Rachel Botsman e Roo Ranger, na obra de economia denominada "O que é seu é meu: como o consumo colaborativo vai mudar o nosso mundo".

Segundo o sistema de serviços de produtos ou "SSSP" há a disponibilização de produtos de uma mesma pessoa, seja ela física ou jurídica, para compartilhamento com outras pessoas, 
também físicas ou jurídicas. Geralmente, os produtos são locados ou os serviços contratados de modo facilitado, como por exemplo, compartilhamento de automóveis (Zipcar, Street Car, Hour Car), compartilhamento de automóveis entre pares (Whipcar, Relay Riders, Getaround), compartilhamento de bicicletas (B-Cycle, Smart Bike, Melbourne Bike Share), aluguel entre pares (Zilok, Rentoid, Ecomodo), aluguel de brinquedos infantis (Dim Dom, Baby Plays, Rent a Toy), aluguel de objetos de moda e acessórios (Bag Borrow or Steal, Fashion Hire, Dressed Up), aluguel de filmes via streaming (Netflix, Lend Around, Quickflix), energia solar (Solar City, Solar Century, Preta Sol) (SASTRE; IKEDA, 2012, p. 06).

Já o sistema do mercado de redistribuição é marcado pela disponibilização por uma pessoa, física ou jurídica, de produtos usados de que sejam titulares ou sejam titulares outras pessoas, para que sejam redistribuídos. Basicamente, verifica-se na troca livre ou troca mediante aquisição e utilização de programas de pontos, monetarizados ou não monetarizados, implicando na possibilidade da reutilização e revenda de produtos que não mais são úteis ao indivíduo. Como exemplos, temos a troca de livros, cd's e vinis, brinquedos, roupas etc (SASTRE; IKEDA, 2012, p. 06).

Conforme Priscila Sastre e Ana Akemi (2012, p. 06), vários sites existem para a facilitação desse tipo de mecanismo: grandes mercados (Craig's List, Gumtree, eBay), troca livre (Around Again, Freecycle, Freeally), troca de livros (Text Book Exchange, Book Hopper, Read It Swap It), troca de brinquedos infantis (Toy Swap, Thread Up, Mum Swap), troca de roupas (Swap Style, Big Wardrobe, Clotihing Exchange), troca de mídias (Swap, Swap Simple, Swapster), troca e empréstimo de ebooks (Book Lending, Lendle, eBook Fling).

Por fim, temos o estilo de vida colaborativo, cuja consubstanciação está na troca de bens tangíveis como o dinheiro, habilidades, tempo e o espaço. Nessa forma, embora pareça estranho, está se tornando cada vez mais comum indivíduos cederem tempo para passear com cães em grandes cidades, locar ou dar em comodato vagas de garagem ou quartos/dormitórios em suas residências para receber estudantes, turistas, intercambiários ou trabalhadores, e até mesmo, ferramentas de financiamento popular e coletivo, com ou sem remuneração. Evidentemente que nessa hipótese se exige alto grau de confiança, o que prejudica de certa forma sua expansão (SASTRE; IKEDA, 2012, p. 06).

Como exemplos, citemos os espaços de coworking (The Hub, Bees Office, Hub Culture), empréstimos sociais entre os indivíduos (Zopa, Prosper, Funding Circle), moedas sociais (Quid, Time Banks, Vem), crowdfunding (Catarse, Movere, Kickstarter), caronas (Zimride, Lift Share, Karzoo), caronas de táxi (Taxi Share, Weeels, Taxi Deck), viagens (Couch Surfing, AirBnB, One 
Fine Stay), compartilhamento de jardins (Urban Garden Share, Land Share, Shared Earth), refeições compartilhadas (Eat with Me, House Bites), trocas de favores (Trade a Favor, Fiverr, Hey Neighbor!) etc (SASTRE; IKEDA, 2012, p. 06).

A comunidade de escambo na Internet vem crescendo rapidamente. São cerca de 500 (quinhentos) escambos online na América do Norte e na América Latina, entre intercâmbios menores, voltados para uma comunidade específica, e grandes intercâmbios abertos. Apenas em 2008, o equivalente a mais de US\$10.000.000.000,00 (dez bilhões de dólares americanos) em mercadorias foram trocados por mais de 400 (quatrocentas) mil empresas globalmente (BOTSMAN; ROGERS, 2011, p. 132).

Não há, contudo, como se prever os rumos que seguirá o consumo colaborativo. Não é possível dizer quanto, quão longe e quão rápido ele vai crescer, mesmo em face das fortes tendências de evolução deste fenômeno socioeconômico até 2015. Não se trata, certamente, de uma iniciativa que vai contra as empresas, pois estas continuarão vendendo e as pessoas continuarão comprando. As expectativas são de uma melhora no perfil dos consumidores e na maneira de consumir, bem como um afastamento da cultura hiperindividualista (BOTSMAN; ROGERS, 2011, pp. 150-151).

Dentro dessas orientações fundamentais do consumo, pode-se afirmar que, sem focar numa estratégia única, de criação de emprego, de direto à renda ou de repartição do trabalho, a economia solidária apresenta-se como uma estratégia de multiplicação das formas de trabalho, sem a pretensão de oferecer uma solução mágica de saída da crise, mas contribuindo à custa de esforços de modelização, de avaliação, de trocas, considerando uma maior visibilidade das relações entre a economia e a sociedade, como um desafio democrático (FRANÇA FILHO; LAVILLE, 2004, p. 93).

A vocação de tais iniciativas é exatamente combinar a dimensão pública da economia com a força dos laços comunitários da sociedade, resultando em dinâmicas comunitárias abertas à alteridade e espaços públicos de proximidade (FRANÇA FILHO; LAVILLE, 2004, p. 20).

A internet vem como recurso principal para a expansão dos instrumentos de consumo colaborativo a serviço da sustentabilidade social, ambiental e econômicas; entretanto, a confiança é o fio condutor dessas relações que se não possam ser denominadas de novas, constituem uma revisitação ou relançamento dos negócios jurídicos, tal como já assinalou Enzo Roppo em sua clássica obra (ROPPO, 1998, pp. 331-342).

De mais a mais, é preciso reconhecer que o desenvolvimento não precisa ser contraditório com a sustentabilidade. Essa conciliação é possível desde que o desenvolvimento 
se converta num afastamento de tudo aquilo que aprisiona e bloqueia o florescimento integral dos seres vivos. Por este caminho de reestruturação, o desenvolvimento torna-se sustentável, contínuo e duradouro (FREITAS, 2012, p. 42).

Felizmente, existe hoje uma nova consciência de que é possível se utilizar, para a mensuração do desenvolvimento de um país, indicadores alternativos mais confiáveis que o PIB, o qual, ao seu tempo, representou um considerável progresso, apesar de simples e limitado em sua métrica sintética, mas que demanda reformulações, a considerar, inclusive, a sustentabilidade, como um dos fatores na avaliação da performance econômica (FREITAS, 2012, pp. 42-43).

Ter um dos maiores PIB do mundo, por exemplo, não significa necessariamente desenvolvimento, do ponto de vista que tal índice não mede a qualidade de vida dos cidadãos, a renda per capta, a probidade nas relações públicas e privadas, a qualidade educacional, o respeito à biodiversidade, a confiabilidade do ambiente negocial etc (FREITAS, 2012, p. 43).

Importante se frisar a indispensabilidade de se construir um critério de avaliação líquida e qualitativa da atividade econômica, tarefa de fôlego, se consideradas as fortes resistências culturais e preconceitos a sobrepujar, que impedem que aflorem as verdadeiras prioridades constitucionais, prendendo-nos numa visão pessimista e sem soluções sobre o futuro, pouco criativas (FREITAS, 2012, p. 43).

\section{CONCLUSÃO}

A pós-modernidade trouxe consigo o remodelamento das relações empresariais e também das relações de consumo, mas que também proporcionaram o nascimento de novos valores sociais, de cunho capitalista ou industrialista, que tornaram a sociedade na busca incessante pelo ter, prazer e poder, certo que, o interesse social que outrora pautava-se na satisfação de interesses necessários foi substituído por um modelo de satisfação de interesses secundários, mas que na ótica da sociedade moderna não são menos importantes, mas que tudo deve ser relativizado, na incansável busca do ter, do prazer e do poder.

$\mathrm{Na}$ atualidade, verifica-se que a relação de consumo, cada vez mais crescente, contribui para o progresso e desenvolvimento social, político e econômico, mas de outro giro, há que se ter em mente que a preocupação da nova relação de consumo é perene, fugaz e substituível, de modo que outro problema arvorece, a construção de uma sociedade individualista, egoísta, e que coloca em xeque a sustentabilidade do planeta, da economia e das próprias relações 
humanas. É necessário o debate e propor novas abordagens, vez que a transformação das relações de consumo pode conduzir à desarmonização social, política e econômica, produzindo reflexos deletérios e imensuráveis.

O ponto de chegada é desconhecido, assim como seus efeitos. Por isso, a fim de evitar o colapso, constatou-se que a atividade empresária deve obediência não apenas às expectativas sociais, vislumbradas pela sua função social, mas deve, atualmente, ocupar-se de promover o desenvolvimento social e econômico, sem descurar da indispensável preservação dos recursos naturais do planeta, para a realidade posta das gerações presentes e futuras. Nesse norte, prepondera a função solidária da empresa, construída à luz regente da sustentabilidade.

A sustentabilidade pode ser dimensionada em social, ambiental e econômica, em nessa quadra, a nova - ou não tão nova - construção do consumo colaborativo é medida que sugere a conscientização e remodelação das relações consumeristas, com vistas a assegurar o postulado da solidariedade constitucionalmente previsto no artigo 3으, inciso I. Indubitavelmente, a república deve ser igualitária, livre e justa; justiça que ao nosso sentir deve ser distributiva e retributiva.

\section{REFERÊNCIAS}

BAUMAN, Zygmunt. Vida para consumo: A transformação de pessoas em mercadorias. Rio de Janeiro: Zahar, 2008.

BOBBIO, Norberto. Teoria Geral da Política: a filosofia política e as lições dos clássicos. Rio de Janeiro: Campus, 2000, p. 101.

BOSTMAN, Rachel; ROGERS, Roo. O que é meu é seu: como o consumo colaborativo vai mudar o nosso mundo. Trad. Rodrigo Sardemberg. Porto Alegre: Bookman, 2011

BRASIL. Constituição da República Federativa do. Disponível em: <http://www.planalto.gov.br/ccivil_03/constituicao/constituicaocompilado.htm>. Acesso em 03 dez. 2016.

Lei no 10.406, de 10 de janeiro de 2002. Disponível em: <http://www.planalto.gov.br/ccivil_03/LEIS/2002/L10406.htm>. Acesso em 03 dez. 2016.

CAMPELLO, Lívia Gaigher Bósio e SANTIAGO, Mariana Ribeiro. A ascensão da troca: um instrumento do consumo colaborativo e sustentável. In: Empresa, sustentabilidade e funcionalização do direito. TYBUSCH, Jerônimo Siqueira et al. (Org.). Florianópolis: JUNJAB, 2013.

CARDOSO, Alenilton da Silva. Princípio da solidariedade: o paradigma ético do direito contemporâneo. São Paulo: Juarez de Oliveira, 2010. 
DI LORENZO, Wambert Gomes. Teoria do Estado de solidariedade: da dignidade da pessoa humana aos seus princípios corolários. Rio de Janeiro: Elsevier, 2010

ELKINGTON, John. Sustentabilidade: canibais com garfo e faca. São Paulo: M. Books, 2011.

FILHO, Calixto Salomão. Função social do contrato: primeiras anotações. Revista de Direito Mercantil, Industrial, Econômico e Financeiro. Ano XLII, no 132. Rio de Janeiro: Malheiros, 2003.

FILHO, Gilberto Montibeller. Ecodesenvolvimento e desenvolvimento sustentável. Disponível em: $<$ https://periodicos.ufsc.br/index.php/economia/article/download/6645/.../08/2011>. Acesso em 04 dez 2016.

FRANÇA FILHO, Genauto Carvalho de e LAVILLE, Jean-Louis. A economia solidária: uma abordagem internacional. Porto Alegre: Editora da UFRGS, 2004.

FREITAS, Juarez. Sustentabilidade: direito ao futuro. 2 ed. Belo Horizonte, Fórum, 2012.

GIDDENS, Anthony. As conseqüências da modernidade. Traduzido por Raul Fiker. São Paulo: UNESP, 1991.

GONÇALVES, Carlos Roberto Gonçalves. Direito civil brasileiro: direito das coisas. 11.ed. São Paulo: Saraiva, 2016.

HABERMAS, Jürgen. Aclaraciones a la ética del discurso. Madrid: Trotta, 2000.

LIPOVETSKY, Gilles. A felicidade Paradoxal. Ensaio sobre a sociedade do hiperconsumo. Lisboa: Edições 70, 2007.

MORAIS, Marcelo Maurício de. Laissez faire, laissez aller, laissez passer Le Monde vá de lui même? Disponível em: http://www.faculdadedesaopaulo.edu.br/centrovelho/downloads/publicacoes/artigoRetornoPo liticaTrabalho090412.pdf. Acesso em 29 set. 2016.

MORIN, Edgar. O Método VI: ética. 2. ed. Tradução de Juremir Machado da Silva. Porto Alegre: Porto Alegre: Sulina, 2005

ROPPO, Enzo. O contrato. Coimbra: Almedina, 1998.

RIZZARDO, Arnaldo. Contratos. 15.ed. São Paulo: Método, 2015.

SANTIAGO, Mariana Ribeiro; CAMPELLO, Livia Gaigher Bósio. Função social e solidária a empresa na dinâmica da sociedade de consumo. Scientia luris, Londrina, v. 20, n. 1, p.119-143, abr. 2016.

SANTIAGO, Mariana Ribeiro; MACHADO, Pedro Antonio de Oliveira. Empresa, sustentabilidade e responsabilidade social: origens, motivações, críticas e aspectos práticos. Disponível em: $<$ www.conpedi.org.br/publicacoes/66fs/345/ndtl7u8I/ZfH4D8uq80F2Fe4v.pdf>. Acesso em 03 dez. 2016. 
SASTRE, Priscila Tereza de Nadai; IKEDA, Ana Akemi. Reflexões sobre Consumo Colaborativo. Anais do XXXVI Encontro da Associação Nacional de Pesquisa de Pós-graduação e Pesquisa em Administração. Rio de Janeiro: ANPAD, 2012.

SILVA, José Afonso da. Comentário contextual à Constituição. 6. ed. São Paulo: Malheiros, 2009.

SILVEIRA, Vladmir Oliveira da; RIBEIRO, Elenice Baleeiro Nascimento. Ética: conteúdo da responsabilidade corporativa e desdobramento da função solidária da empresa. Curitiba: Revista da Unicuritiba, 2016, p. 10.

STOLFI, Giuseppe. Manuale di Diritto Civile e Comerciale. v. 1. Milão: Giuffrè, 1957.

Trabalho enviado em 19 de janeiro de 2017.

Aceito em 02 de abril de 2017. 